\title{
A New Model for Accessible Formats in the Public Library
}

Kim Johnson, Public Library Services Branch, Government of Alberta

Sabina Iseli-Otto, National Network for Equitable Library Service (NNELS), Canada

Keywords: accessible format; format shift; print disability; public library; user-driven

Publication Type: poster

\begin{abstract}
Those of us in the library community and the literary community, both as providers and content creators, know how important books are for readers. Books offer the opportunity for lifelong learning, community-building, and recreation as well as for political engagement and opportunities for civil discourse. People who are unable to access traditional formats because of a print disability should have access to books as tools of pleasure and revolution in the same way that typical readers do. Yet, it is estimated that only $5-7 \%$ of published material is available in accessible formats. Furthermore, people with print disabilities have a complex relationship with public libraries, as the public library has not always been empowered to meet their needs or to be able to treat them as any other patron.
\end{abstract}

The National Network for Equitable Library Service (NNELS, https://nnels.ca/) offers a technologically forward, democratic, and participatory network that aims to address these inequities. NNELS is an online public library of books in accessible formats for readers with print or perceptual disabilities. The Canadian Copyright Act (1985) defines a perceptual disability as a disability that prevents or inhibits a person from reading or hearing a literary, musical, dramatic or artistic work in its original format and includes such a disability resulting from

- (a) severe or total impairment of sight or hearing or the inability to focus or move one's eyes,

- (b) the inability to hold or manipulate a book, or

- (c) an impairment relating to comprehension.

NNELS produces accessible format books in a distributed network, using open-source technology to offer a user-driven digital service for public library users with print disabilities. Instead of creating a collection for people with print disabilities based on assumptions about what they would like to read, the NNELS team records and format-shifts material that people with print disabilities have requested. The emphasis on user-driven production puts curation and demand directly in the hands of the user and offers unique ways of consulting and engaging people with print disabilities to build a service that works for their needs while enabling them to feel like every other public library user.

NNELS represents a world-first approach in both its technology (open source; authentication) and in its approach (user-driven collection development). NNELS is a distributed network that empowers libraries to be part of production and communication and service delivery. NNELS also takes the network principle seriously: individual volunteers may on their own, or as a library project, record books for the NNELS collection. Anyone is welcome to record a book for 
NNELS. All of these materials (library-created or NNELS-created) are added to the NNELS repository to build a collection as unique in its diversity as its users are in their reading preferences.

Since its inception in 2014, NNELS has built a collection of over 11,000 items. NNELS has been able to offer its users access to award-winning books in accessible formats on the same day they are released (for example, the Governor General's shortlist, CBC Canada Reads long list, etc.). Additionally, NNELS has been able to produce in a timely manner accessible copies of documents that are crucial to civil discourse and political engagement, such as the Truth and Reconciliation Reports (produced in accessible format in both French and English thanks to hundreds of hours of work from the NNELS staff), many Indigenous-authored works, as well as provincial government documents. NNELS also makes available material that is often overlooked, such as medical information and instructional books. In a perfect world, all published material would be available in any format a reader requires, but we are not there yet. NNELS is working with libraries, service providers, and volunteers to build a sustainable model that will address this inequity and that puts the power in the hands of the user.

Our poster presents an overview of the NNELS initiative and describes how this model has the potential to revolutionize public library service for people with disabilities, as a tool for empowerment beyond engagement. The poster also lays out the challenges and opportunities within this model and describes the speculations on how the model has the potential to address other kinds of diversity challenges in public libraries.

\section{The following references were consulted in the preparation of the abstract and poster.}

The Canadian Copyright Act. (1985). Copyright Act, R.S.C c. C-42., § 2. Retrieved from http://laws-lois.justice.gc.ca/eng/acts/C-42/page-1.html.

The National Network for Equitable Library Service: The Canadian Accessible Library System (NNELS). Retrieved from https://nnels.ca/.

Kim Johnson (kimberly.johnson@gov.ab.ca) is a consultant for the Public Library Services Branch with the Government of Alberta. Kim works on resource sharing initiatives, such as Alberta-Wide Borrowing, interlibrary loan, and library services for people with print disabilities.

Sabina Iseli-Otto (sabina@nnels.ca) is the Public Services Librarian for the National Network for Equitable Library Service (NNELS). Sabina works with librarians across Canada to help provide material in accessible formats for patrons with print disabilities. If you call the NNELS help line, chances are you will reach Sabina (and she will be happy to talk to you!). She is also interested in bicycles, her dog Chelsea, and everything related to expanding the information commons. 